\title{
Congenital hepatic fibrosis
}

\author{
H. J. F. HODGSON, D. R. DAVIES, AND R. P. H. THOMPSON ${ }^{1}$
}

From St Thomas' Hospital, London SE1

SYNOPSIS During 10 years four patients with congenital hepatic fibrosis were seen in a general hospital in London; three presented in adult life. It is suggested that the condition may account for a larger proportion of patients with chronic liver disease than has been thought to be the case.

In 1961 Kerr et al separated congenital hepatic fibrosis from other types of 'juvenile cirrhosis'. They emphasized the histological appearances of the liver, namely, normal lobules of parenchyma separated by broad bands of fibrous tissue, abnormal interlobular bile ducts which were multiple and dilated, and scarce portal veins, and also the association with renal abnormalities. More than 150 cases of this condition have now been reported (Sommerschild et al, 1973). The presentation between birth and early adult life, the rarity of the condition, and the good prognosis have often been emphasized. Indeed, in this country in 1972 only 20 cases were known to a team surveying the condition (Okonkwo and Choa, 1972), but it may not be as rare as this, especially since some cases are misdiagnosed as cirrhosis (Kerr et al, 1962; Campana et al, 1974).

In this paper we describe four more patients, only one of whom was referred from outside the hospital's district, while three were more than 30 years old at the time of diagnosis. It is suggested that, due to its incorrect diagnosis, the condition may be more common than is usually thought.

\section{Case Reports}

\section{PATIENT 1}

A 36-year-old technical writer was admitted to St Thomas' Hospital in 1966 for investigation of two episodes of severe haematemesis and melaena over six months. Splenomegaly had been noted at the age of 20 years. There was no relevant family history.

On examination there was hepatosplenomegaly. Investigations showed: serum alkaline phosphatase 15-25 King-Armstrong units/dl (normal <14 KA

${ }^{1}$ Requests for reprints to Dr R. P. H. Thompson, St Thomas' Hospital, London SE1.

Received for publication 17 July 1975. units/dl), serum bilirubin and aspartate aminotransferase (SGOT) levels normal, plasma urea $7.9 \mathrm{mmol} / 1$ (normal $7.0 \mathrm{mmol} / 1$ ), creatinine clearance $56 \mathrm{ml} /$ min. Oesophagoscopy and radiology showed oesophageal varices.

An elective end-to-side portal-caval anastomosis was performed. At operation portal venous pressure was $4.1 \mathrm{kPa}(31 \mathrm{mmHg})$. The liver was enlarged and fibrotic, and there were many small cysts in the kidneys. The extrahepatic biliary tree was normal. The histological appearances of a wedge biopsy specimen of the liver were thought to show inactive cirrhosis with nodular regeneration, the normal architecture being broken up by broad fibrous bands containing dilated bile ducts, but these appearances were later interpreted as those of congenital hepatic fibrosis (fig 1).

He remained well for thr ee years when ataxia and difficulty in concentration developed. These improved on a low-protein diet with oral neomycin and lactulose therapy. In 1972 he complained of dyspepsia, loin pain, and haematuria. Radiology and endoscopy showed duodenal ulceration but no varices. Intravenous pyelography showed the kidneys to be of normal size, with multiple areas of punctate calcification and cysts $1-2 \mathrm{~cm}$ in diameter, mainly in the medulla. Creatinine clearance was $42 \mathrm{ml} / \mathrm{min}$, serum bilirubin 22.3-44.5 $\mu \mathrm{mol} / 1$ (normal $<17 \mu \mathrm{mol} / \mathrm{l}$ ); alkaline phosphatase 16-23 KA units/dl; aspartate aminotransferase $90 \mathrm{iU} / 1$ (normal $<60 \mathrm{iU} / 1$ ). To avoid further surgery, 2000 rads cobalt teletherapy were given to the stomach. Maximal acid output in response to pentagastrin (Johnston and Jepson, 1967) was reduced from 31.3 to $12.8 \mathrm{mEq} /$ hour and his symptoms improved.

In 1973 increasing encephalopathy prevented him from working and an ileostomy was formed, but he was still unable to continue work. Blood ammonium level on a $20 \mathrm{~g}$ protein diet was $107 \mu \mathrm{mol} / 1$ (normal 


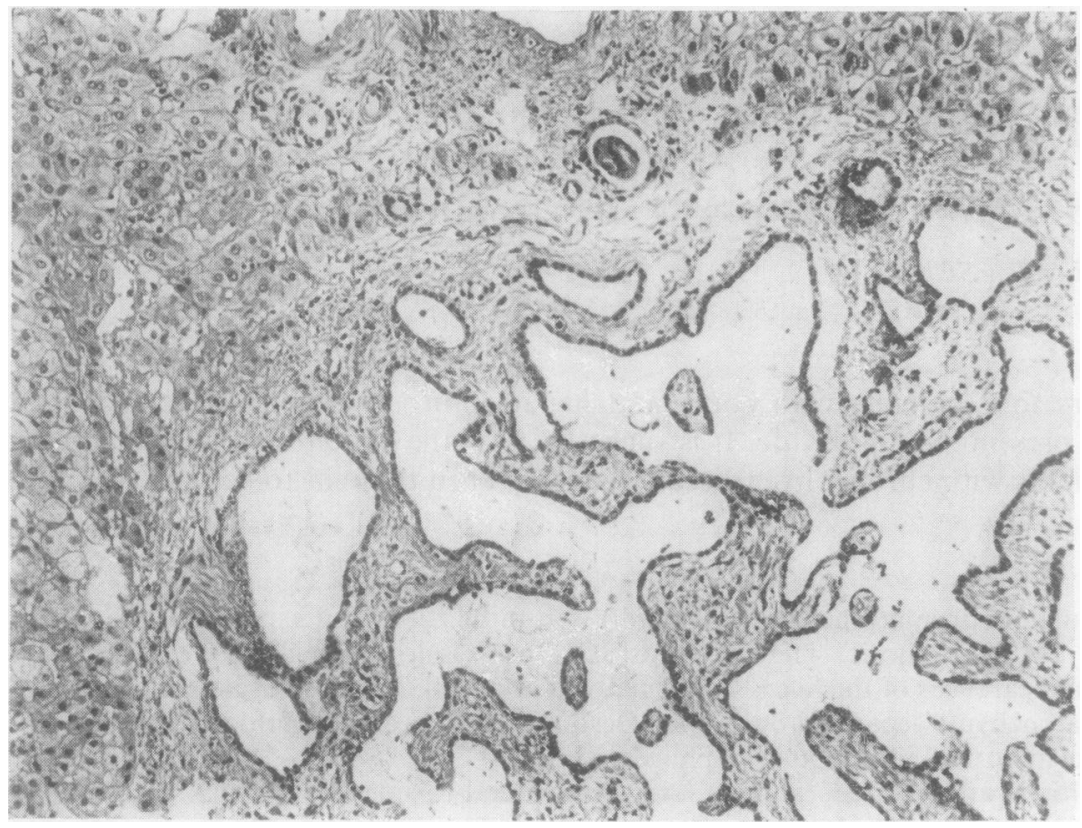

Fig 1 Case I.

Cystically dilated bile ducts surrounded by fibrous tissue in a portal tract. Portal veins are inconspicuous and the portal tracts are fairly well demarcated. Haematoxylin and eosin $\times 120$.

$<70 \mu \mathrm{mol} / 1)$. A total colectomy was performed but he developed hepatic and renal failure and peritoneal sepsis.

At postmortem examination the liver surface was finely nodular, with one $1 \mathrm{~cm}$ cyst on the surface. The histological appearances of congenital hepatic fibrosis were confirmed. The biliary tree was normal. The kidneys showed fetal lobulation, and there was some interstitial fibrosis and many cysts corcentrated in the region of the corticomedullary junction, with a few cortical cysts.

\section{PATIENT 2}

A 15-year-old boy experienced a large haematemesis in 1963. At the age of 3 laparotomy had been performed for bilateral abdominal masses and a diagnosis of Wilm's tumours was made. No biopsy was performed. A brother had polycystic kidneys and his father died of hypertension and renal disease at the age of 56. The patient had hepatosplenomegaly. Radiology revealed oesophageal varices, and intravenous pyelography showed polycystic kidneys. Liver function tests were normal; creatinine clearance was $72 \mathrm{ml} / \mathrm{min}$.

Laparotomy was performed. The liver and spleen were enlarged and oesophageal varices were present. The extrahepatic biliary tree was normal. Portal venous pressure was $3.3 \mathrm{kPa}(25 \mathrm{~mm} \mathrm{Hg})$. The kidneys were polycystic. Associated anomalies were an unusually wide inferior vena cava and redundant small bowel mesentery. An end-to-side portal-caval anastomosis was performed.

Microscopic examination of a wedge biopsy specimen of the liver showed much fibrosis of the portal tracts with minimal infiltration by chronic inflammatory cells. There were excess numbers of bile ducts in the fibrous tissue, some containing bile plugs, and an almost complete absence of portal veins. A diagnosis of congenital hepatic fibrosis was made (figs 2 and 3 ).

Eight years later creatinine clearance was $34-40$ $\mathrm{ml} / \mathrm{min}$ with proteinuria of 3-6 g/24 hours; serum bilirubin was normal, alkaline phosphatase 14-17 KA units/dl, aspartate aminotransferase $85 \mathrm{iU} / \mathrm{l}$.

There has been no recurrence of gastrointestinal bleeding and he remains well.

\section{PATIENT 3}

A 37-year-old man was admitted to another hospital in 1957 with fever, abdominal pain, and jaundice. At the age of 24 he had been admitted to hospital with malaria and hepatosplenomegaly. There was no family history of liver or kidney disease.

He had hepatosplenomegaly. Serum bilirubin was $9.6 \mu \mathrm{mol} / \mathrm{l}$, alkaline phosphatase $52 \mathrm{KA}$ units/dl. A laparotomy was performed, revealing a hard, mottled liver, splenomegaly, and a normal extrahepatic biliary tree. Microscopic examination of a wedge biopsy specimen of the liver was thought to show early biliary cirrhosis. His condition improved spon- 


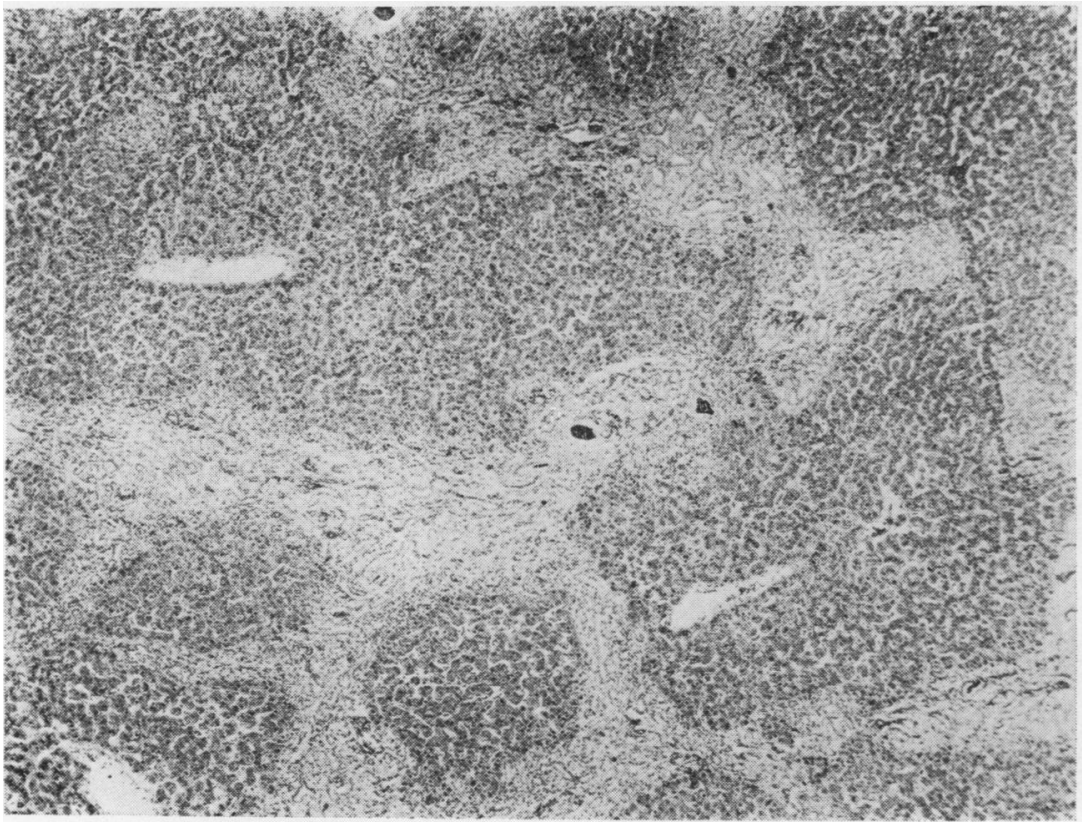

Fig 2 Case 2. Broad bands of fibrous tissue containing many bile ducts surrounding lobules. Some inflammatory cells are present. $H$ and $E \times 36$.

taneously. A year later he had a brief episode of melaena, but oesophageal varices were not found.

In 1970 an intravenous pyelogram revealed a left ureteric stone and clusters of calcification in the left kidney. In both kidneys collecting tubules were opacified, suggesting they were dilated, and the calyces were splayed. A diagnosis of medullary sponge kidney was made. Calcified gall stones were also noted. The ureteric stone was removed at cystoscopy.

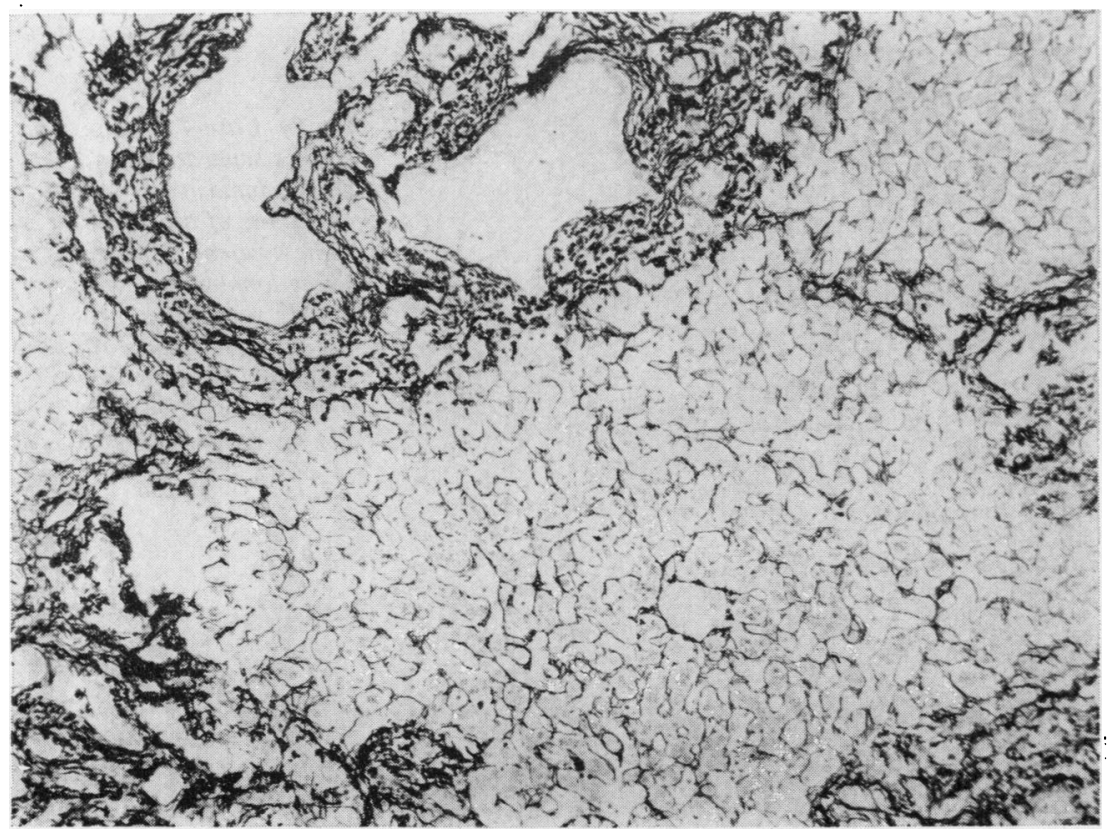

Fig 3 Case 2. A normal relationship of central vein to portal tract is seen. Retic $\times 90$. 


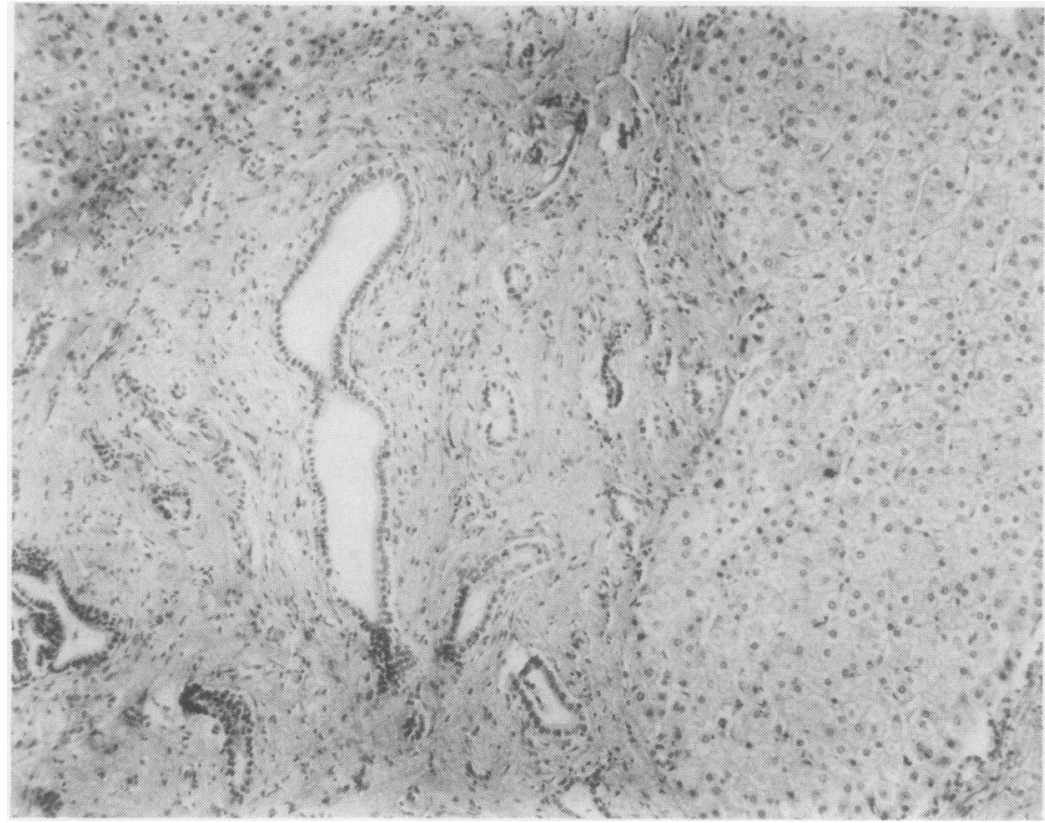

Fig 4 Case 3. Plentiful bile ducts present in a wide band of fibrous tissue. Portal veins are inconspicuous, and the limiting plate of the lobule is sharp. $H$ and $E \times 90$.

Between 1967 and 1972 he had four attacks of painless, afebrile jaundice. In 1972 an endoscopic retrograde cholangiogram showed that the common bile duct was grossly dilated and contained many stones, as did the gall bladder. The intrahepatic bile ducts were irregular but only slightly dilated. At laparotomy the liver and spleen were enlarged; the stones were removed and cholecystectomy was performed. Microscopic examination of a wedge biopsy specimen of the liver showed preservation of the

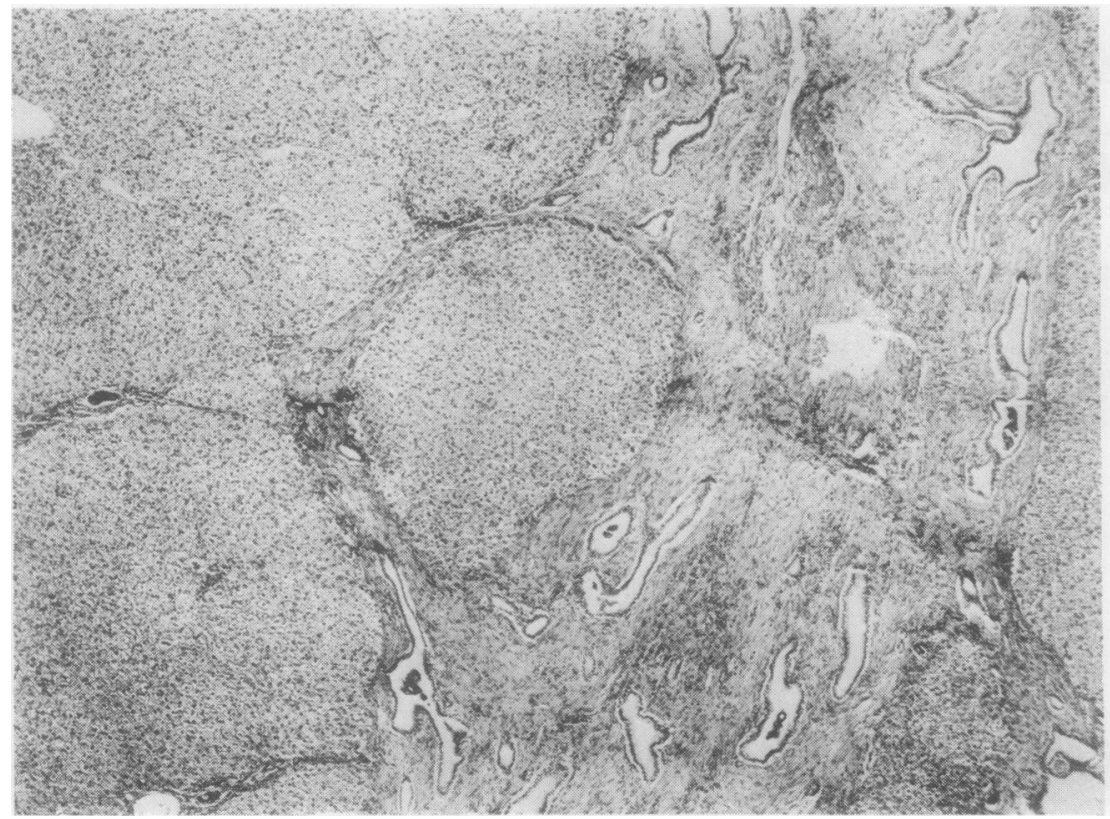

Fig 5 Case 4. Liver lobules separated by fibrous bands containing an excess of bile ducts, some cystically dilated. Some lobules are completely surrounded by fibrous tissue while others have apparently normal portal tracts with little fibrous tissue. $H$ and $E$ $\times 36$. 
lobular pattern with broad connective tissue bands containing many small bile ducts typical of congenital hepatic fibrosis (fig 4).

Subsequently he has remained free of symptoms, although liver function tests remain abnormal; serum bilirubin $1-4 \mathrm{mg} / \mathrm{dl}$, alkaline phosphatase 29 KA units/dl, aspartate aminotransferase $100 \mathrm{iU} / 1$. Plasma urea normal.

\section{PATIENT 4}

A 24-year-old man presented to St. Thomas' Hospital in 1965 with epigastric pain. Radiology showed a duodenal ulcer. There was moderate proteinuria but liver function tests were normal. His father had died in his thirties from 'Bright's disease', and his sister at the same age from cholangitis associated with congenital hepatic fibrosis and polycystic kidneys.

Three years later hepatosplenomegaly and pes cavus were noted. Plasma urea was $\mathbf{9} \cdot \mathbf{0}-10.6 \mathrm{mmol} / \mathbf{1}$ and creatinine clearance $72 \mathrm{ml} / \mathrm{min}$. An intravenous pyelogram showed loss of substance of the lower pole of the right kidney. The histological appearances of a percutaneous biopsy specimen of the kidney were glomerular hyalinization and periglomerular fibrosis with atrophy and cystic dilatation of tubules, and interstitial fibrosis with inflammatory change.

In 1973 endoscopy showed a duodenal ulcer but no varices. Plasma urea was $9.0 \mathrm{mmol} / \mathrm{l}$, creatinine clearance $51 \mathrm{ml} / \mathrm{min}$, proteinuria $4.5 \mathrm{~g} / 24$ hours; liver function tests were normal. A partial gastrectomy was performed, and an enlarged liver and bosselated kidneys were found. The extrahepatic biliary tree was normal. Following the operation liver function tests remain normal.

Microscopic examination of a wedge biopsy specimen of the liver showed preservation of the lobular architecture, with thick fibrous bands, abnormal dilated bile ducts, and reduced numbers of portal veins (fig 5).

\section{Discussion}

It has been suggested that congenital hepatic fibrosis represents several clinically and genetically distinct conditions that may be separated on the basis of their renal lesions (Murray-Lyon et al, 1973). But if the patient does not develop the severe renal lesions of the younger childhood types (Blyth and Ockenden, 1971) he survives and develops the liver lesion. Hepatic fibrosis is therefore associated with various milder forms of renal tubular ectasia that may be modified by secondary ischaemia or infection. Thus in the adult a variable degree and type of renal disease is found; it was minimal in patients 1 and 3 and more marked in cases 2 and 4. The radiological appearances of medullary sponge kidney (renal tubular ectasia) (Kerr et al, 1962), kidney dysplasia (Ivemark et al, 1959), and medullary cystic disease (probably identical with nephronophthisis) (Boichis et al, 1973) have all been reported, but it is not easy to classify precisely the type of renal lesion in these four cases. In patient 1 the anatomical appearances were closest to those of medullary cystic disease, although the clinical features (Strauss, 1962) were lacking. On clinical grounds it seems likely that patient 2 had polycystic disease of the kidneys of juvenile type, and patient 3 showed the pyelographic appearances of medullary sponge kidney, but we have insufficient information to classify the renal lesion of patient 4 .

The histological appearances of the liver and the association with renal disease in our patients are typical of the syndrome but in three the age of onset is unusually late. Patient 1 presented with his first haematemesis at the age of 36 , patient 4 was not correctly diagnosed until 32 , and patient 3 until 52 , having presented at 37 . Presentation in the fourth decade has been described but is unusual (Lorimer et al, 1967). Late presentation may lead to a wrong diagnosis of cirrhosis, and this occurred for several years in two of our patients. One reason for this (as in patient 1) is that a small biopsy specimen may not contain sufficient portal tracts for the characteristic lesion to be seen, and fibrous bands in a fragmented specimen may mislead. A second pitfall is that polymorphonuclear and other inflammatory cells may be present in the abnormal portal tracts when cholangitis occurs. The combination of cholangitis and large numbers of bile ducts may suggest bilia1y cirrhosis, and this was the cause of the original misdiagnosis in case 3.

Two patients had duodenal ulcers. Peptic ulcers were also present in two of the children reported by Kerr et al (1961), and peptic ulcers are known to be frequent in patients with alcoholic cirrhosis (Fainer and Halsted, 1955). Dyspepsia developed after the portal-caval anastomosis in patient 1 , but although peptic ulceration after shunt procedures has been noted (Hourigan et al, 1971; Brown and Walker, 1967), there is no definite evidence that the incidence is higher than expected (Phillips et al, 1975). The importance of peptic ulcers in patients at risk from bleeding oesophageal varices is well recognized (Fainer and Halsted, 1955).

Murray-Lyon et al (1972) have re-emphasized the association of congenital hepatic fibrosis with dilatation of the intra and extrahepatic biliary tree; such a syndrome was probably present in the sister of patient 4 . The extrahepatic biliary tree was normal at operation in patients 1,2 , and 4 , and the intrahepatic ducts were normal at necropsy in patient 1 . In patient 3 the common bile duct was dilated but the 
intrahepatic ducts only slightly so, and this was interpreted as due to the stones in the bile duct.

In patient 1 hepatic encephalopathy developed after a shunt operation which, by reducing liver blood flow, may have accelerated the progressive deterioration of liver function (Zeegen et al, 1970) and the second operation precipitated liver and renal failure; recently, Keighley et al (1973) found that in children undergoing shunt procedures postoperative liver failure and encephalopathy were more common in those with congenital hepatic fibrosis than in those with cirrhosis.

The prevalence of hepatic fibrosis is unknown, and misdiagnosis of patients as having cirrhosis, which occurred in two of our patients, will falsely reduce it. Patient 3 had an unnecessary laparotomy before the correct diagnosis was made. Specialized hospital units will see a disproportionately high number of cases, but our four patients were seen in a hospital when it was without a special interest in liver disease during a decade in which 120 patients with non-alcoholic chronic liver disease were also seen. Four cases may be fortuitous, but we nevertheless suggest that this condition may be more common than is generally recognized. In spite of the complexity of the associated renal lesions, the single syndrome of congenital hepatic fibrosis remains a valuable diagnosis.

We are grateful to the physicians of this hospital for allowing us to report the patients under their care and to Mr A. E. Clark for the photographs.

\section{References}

Blyth, H. and Ockenden, B. G. (1971). Polycystic disease of kidneys and liver presenting in childhood. J. med. Genet., 8, 257-284.

Boichis, H., Passwell, J., David, R., and Miller, H. (1973). Congenital hepatic fibrosis and nephronophthisis. Quart. J. Med., 42, 221-233.

Brown, G. J. A. and Walker, R. M. (1967). Portacaval anastomosis. Lancet, 2, 854-856.

Campana, H. A., Park, Y. S., and Gourgoutis, G. D. (1974). Congenital hepatic fibrosis: two cases simulating hepatic cirrhosis. Amer.J. dig. Dis., 19, 325-333.

Fainer, D. C. and Halsted, J. A. (1955). Sources of upper alimentary tract hemorrhage in cirrhosis of the liver. $J$. Amer. med. Ass., 157, 413-414.

Hourigan, K., Sherlock, S., George, P., and Mindel, S. (1971). Elective end-to-side portacaval shunt. Brit. med. J., 4, 473-477.

Ivemark, B. L., Oldfelt, V., and Zetterström, R. (1959). Familial dysplasia of the kidneys, liver and pancreas: a probably genetically determined syndrome. Acta. paed. scand. (Uppsala), 48, 1-11.

Johnston, D. and Jepson, K. (1967). Use of pentagastrin in a test of gastric acid secretion. Lancet, 2, 585-588.

Keighley, M. R. B., Girdwood, R. W., Wooler, G. H., and Ionescu M. I. (1973). Long-term results of surgical treatment for bleeding oesophageal varices in children with portal hypertension. Brit.J. Surg., 60, 641-646.

Kerr, D. N. S., Harrison, C. V., Sherlock, S., and Walker, R. M. (1961). Congenital hepatic fibrosis. Quart. J. Med., 30,91-117.

Kerr, D. N. S., Warrick, C. K., and Hart-Mercer, J. (1962). A lesion resembling medullary sponge kidney in patients with congenital hepatic fibrosis. Clin. Radiol., 13, 85-91.

Lorimer, A. R., McGee, J., and McAlpine, S. G. (1967). Congenital hepatic fibrosis. Postgrad. med. J., 43, 770773.

Murray-Lyon, I. M., Ockenden, B. G., and Williams, R. (1973). Congenital hepatic fibrosis-is it a single clinical entity? Gastroenterology, 64, 653-656.

Murray-Lyon, I. M., Shilkin, K. B., Laws, J. W., Illing, R. C., and Williams, R. (1972). Non-obstructive dilatation of the intrahepatic biliary tree with cholangitis. Quart. J. Med., 41, 477-489.

Okonkwo, S. and Choa, G. (1972). Congenital hepatic fibrosis. (Letter). Lancet, $2,829$.

Phillips, M. M., Ramsby, G. R. and Conn, H. O. (1975). Portacaval anastomosis and peptic ulcer; a non-association. Gastroenterology, 68, 121-131.

Sommerschild, H. C., Langmark, F., and Maurseth, K. (1973). Congenital hepatic fibrosis: report of two new cases and review of the literature. Surgery, 73, 53-58.

Strauss, M. B. (1962). Clinical and pathological aspects of cystic disease of the renal medulla. Ann. intern. Med. 57, 373-381.

Zeegen, R., Stansfeld, A. G., Dawson, A. M., and Hunt, A H. (1970). Prolonged survival after portal decompression of patients with non-cirrhotic intrahepatic portal hypertension. Gut, 11, 610-617. 